\title{
Confocal Raman Microscopy Study of Food Microstructures
}

\author{
Jinping Dong ${ }^{1}$
}

${ }^{1}$ Cargill Inc., Research \& Development - Ingredient, Material, and Nutrition (IMN), Plymouth, MN

Understanding and controlling the food microstructure to achieve desired texture and nutrition leads in recent trends in food research. Many microscopic tools are being employed by industrial and academic researchers to reveal the morphology and chemical distribution of the food and ingredient systems. Confocal Raman microscopy is a chemical imaging tool that was recently introduced to the food area, and has gained significant interest among food scientists.

Raman spectroscopy provides the chemical fingerprint of a molecule irradiated by a laser. Combining high resolution confocal optical microscopy and Raman spectroscopy, a 3-D chemical map can be obtained from a material under various environmental conditions, reaching a spatial resolution of 200-300 $\mathrm{nm}$ laterally and $\sim 500 \mathrm{~nm}$ vertically. Raman microscopy has been applied to various food systems including emulsions, fat, fiber systems, hydrocolloids, protein-based beverages, etc. [1].

Here we present a study to understand ice crystal formation in a model food system in freezing conditions. Freezing is a common storage method for food [2,3]. Formation of ice crystals leads to a drastic increase of local ingredient concentrations, resulting in irreversible change of physical and possibly chemical structures of the ingredients. A model cellular system was selected to mimic foods from an animal source. Cell suspensions were frozen to $-26^{\circ} \mathrm{C}$ through a Peltier stage under the Raman microscope. Ice seeding of the cell suspension was performed at -3 and $-10^{\circ} \mathrm{C}$ during the cooling to achieve different supercooling conditions. Raman chemical images for each process were generated for ice, organic cellular contents, and cryoprotective agent (i.e., DMSO or sugar) by integrating the characteristic Raman peaks from a collective of Raman spectra obtained by raster-scanning across a single cell.

When cells were frozen in 1xPBS with low supercooling, large ice crystals were observed only in the periphery of the cell, but inside the cell membrane. The center of the cell was concentrated with organic cellular material at a relatively uniform distribution, causing the darkening observed in transmitted light microscopy. At higher supercooling, the cell appeared transparent (not dark) under the light microscope, however, large ice crystals (multiple separate regions) were detected intracellulary. When the cell was frozen in 10\% DMSO solution, large intracellular ice crystals were also formed while the organic cellular material were concentrated between the ice crystals. Note that the crystal size distribution in the $10 \%$ DMSO solution was much narrower than that observed in the high supercooling 1xPBS case. We showed that CRM allows for direct chemical identification of the different thermodynamic phases that form extra/intra-cellularly during different cryopreservation methods, therefore enabling identification of the precise molecular mechanisms of damage in cells.

Figure 1 below shows representative Raman images captured on frozen cells with different degree of supercooling. Clear identification of ice and different cellular components can be easily observed.

\section{References:}


[1] PDA Pudney et al in "The Role of Confocal Raman Spectroscopy in Food Science", in "Applications of Vibrational Spectroscopy in Food Science”, ed. JM Chalmers et al, (Wiley, New York 2010), p.133.

[2] AE Delgado, Da-Wen Sun, Journal of Food Engineering 47 (2001), p. 157.

[3] AJ Miller, SA Ackerman, SA Palumbo, Journal of Food Science 45 (1980), p. 1466.

\begin{tabular}{ccc}
$\begin{array}{c}\text { Transmitted Light } \\
\text { Microscopy }\end{array}$ & $\begin{array}{c}\mathrm{CH}_{2} \text { (Organic) } \\
\left(2800-3000 \mathrm{~cm}^{-1}\right)\end{array}$ & $\begin{array}{c}\text { 1XPBS Ice } \\
\left(3050-3200 \mathrm{~cm}^{-1}\right)\end{array}$ \\
\hline
\end{tabular}
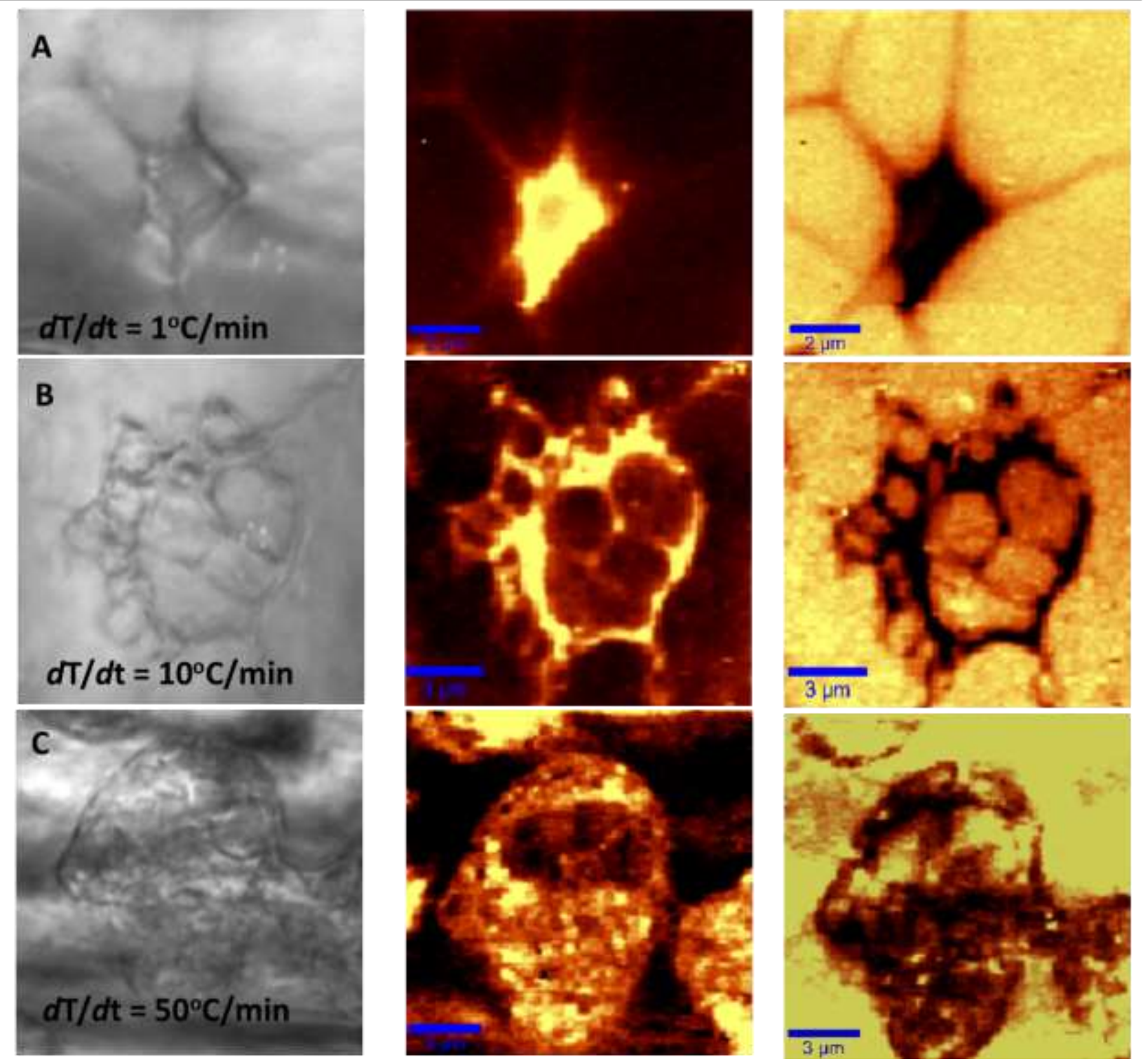

Figure 1. Confocal Raman images on frozen cells : Row A. Cooling rate of $1{ }^{\circ} \mathrm{C} / \mathrm{min}$, no ice crystals were formed inside the cell, and cell size was significantly reduced; Row B. Cooling rate of $10^{\circ} \mathrm{C} / \mathrm{min}$, round ice crystals $(1-3 \mu \mathrm{m})$ were formed inside the cell, and organic matter was concentrated in between ice; Row C. Cooling rate of $50^{\circ} \mathrm{C} / \mathrm{min}$, one large ice crystal took up most of internal cell space. 